\title{
The Design of a TiNi Actuator in an Intramedullary Leg Lengthening Device
}

\author{
A.M.M. Aalsma, E.E.G. Hekman, J.W.J.L. Stapert* and H.J. Grootenboer \\ University of Twente, Faculty of Mechanical Engineering, Laboratory for Biomechanical Engineering, \\ P.O. Box 217, 7500 AE Enschede, The Netherlands \\ * The Universiteit Maastricht, Faculty of Medicine, Maastricht, The Netherlands
}

\begin{abstract}
Today's medical technology makes it possible to increase leg length for people with leg length discrepancies or excessively short limbs. With the llizarov method bones can be gradually elongated (max. $1 \mathrm{~mm} /$ day) without implantation of bone grafts or multiple operations. Although the operative procedure is relatively simple, the negative side effects for the patient are considerable. An external fixator is mounted to the bone. The fixation is made by pins through the skin. Amongst the disadvantages of the external fixator are possible infection of the bone or soft tissue, minimal weight bearing and restricted possibility for wearing clothes. A design for a fully implantable extractor is proposed in order to eliminate these disadvantages for the patient.

An actuator of TiNi alloy is chosen for inducing the displacement of $1 \mathrm{~mm} / \mathrm{day}$. The advantages of such an actuator are the biocompatibility and the small physical dimensions needed, where the maximum diameter of the medulla is only $13 \mathrm{~mm}$. By using the Two Way Shape Memory Effect (TWSME) a very compact and simple actuator is designed. The most important factors in the design of the TWSME-actuator are the elongation, working force and transformation temperatures of the alloy. The TWSME-training method for the actuator used in our tests showed a sufficient generation of force and elongation. Differential Scanning Calometry measurements showed a shift in the transformation temperatures due to the training. This is a result of induced internal stresses by the training. Neither the amount of temperature shift nor the efficiency of the training were correlated to pre-training annealing temperatures $\left(500^{\circ} \mathrm{C}-700^{\circ} \mathrm{C}\right)$.
\end{abstract}

\section{INTRODUCTION}

In the late 1960's a Russian scientist named Ilizarov developed a new method to lengthen long bones like the tibia and the femur [1]. This method was based on the principle that healthy bone can produce new bone cells named callus in the fracture site. This callus tissue can be distracted at a certain rate by application of mechanical stress. The optimum distraction rate is approximately $1 \mathrm{~mm} /$ day. In the clinical application the bone which is to be lengthened will be divided into two sections. After approximately 9 days the callus will have closed the gap, and distraction can be commenced.

The tool Ilizarov designed to perform the distraction of bone parts (the Ilizarov fixator) is an external frame which is to be placed around the leg and connected to the bone through the skin and other soft tissues by screws or wires. The patient is able to elongate the frame and so distract the bone parts from one another. This Ilizarov fixator is still being used in modern surgery. The procedure to install the fixator is relatively simple but time consuming. The medical results are satisfactory and the fixator enables simultaneous elongation and correction of angular deformities of the bone. However the disadvantages for the patient are considerable. Whereas an elongation of $100 \mathrm{~mm}$ is possible, the patient has to wear the fixator for 6 to 10 months depending on his age and health because the fixator is also used for fracture fixation after elongation. The Ilizarov fixator weighs about $3.5 \mathrm{~kg}$ and because of its size it is impossible to wear normal clothing. Furthermore, as a result of the displacement, the screws leave pin tracks in the soft tissue, may damage muscles and nerves, cause restricted movement of the joints and they can be a source of infection in the flesh as well as in the bone which could necessitate removal of the infected bone. Another problem is the flexibility of the pins: they will bend under weight bearing which can cause an unintentional rotation and/or a translation of the bone parts with respect to one another. Besides the 
physical burden it also contributes to a non-negligible mental stress because of the pain and inability to function normal in the patients daily environment.

Improvement has been made by the use of a unilateral fixator. This fixator is mounted on one side of the leg so it is smaller, lighter and easily fitted under the patients clothing. This fixator also requires fewer pins and so reduces risk on infection. A disadvantage is still the inferior stability and the long time it is connected to the patients leg.

By combining the uni-lateral fixator with a intramedullar locking nail [2], the position of the bone parts is defined by the intramedullar locking nail, while the fixator is used for distracting the bone. The big advantages of this system are shorter presence of a external fixator, because it can be removed after the elongation period, and the superior positioning and stability of the bone before and after removal of the external fixator so the patient can start using the leg sooner. The disadvantages are still pin track infection and restricted weight bearing during elongation.

At the Laboratory for Biomechanical Engineering at the University of Twente a design is made for a fully implantable extractor. This extractor should be placed entirely in the medulla of the bone which has a maximum diameter of $13 \mathrm{~mm}$, without any connections through the skin. Advantages of such a device would be: easy implantation procedure, comparable to the standard intramedullar locking nails, no transcutaneous connections and therefore less infection risk, full weight bearing possible shortly after surgery and no discomfort of a external frame mounted to the leg. The absence of the pins or screws also lessens the risk of soft tissue damaging, muscle and nerve damage and reduces the amount of joint contraction.

The intramedullary extractor consists of a telescopic nail which is lengthened by a linear TiNi motor. The TiNi motor consists of a NiTi tube which can change its length due to the Two Way Shape Memory Effect (TWSME) and two NiTi rings which can change their diameter due to the TWSME. By sequel activation of the elements a linear movement of the nail through the motor can be achieved [3]. This paper will focus on a certain part of the design of a linear NiTi motor which will cause the distraction of the bone. This part is a NiTi ring which will be trained for TWSME so it can be loosened from or clamped on a pen to move or carry the patients weight.
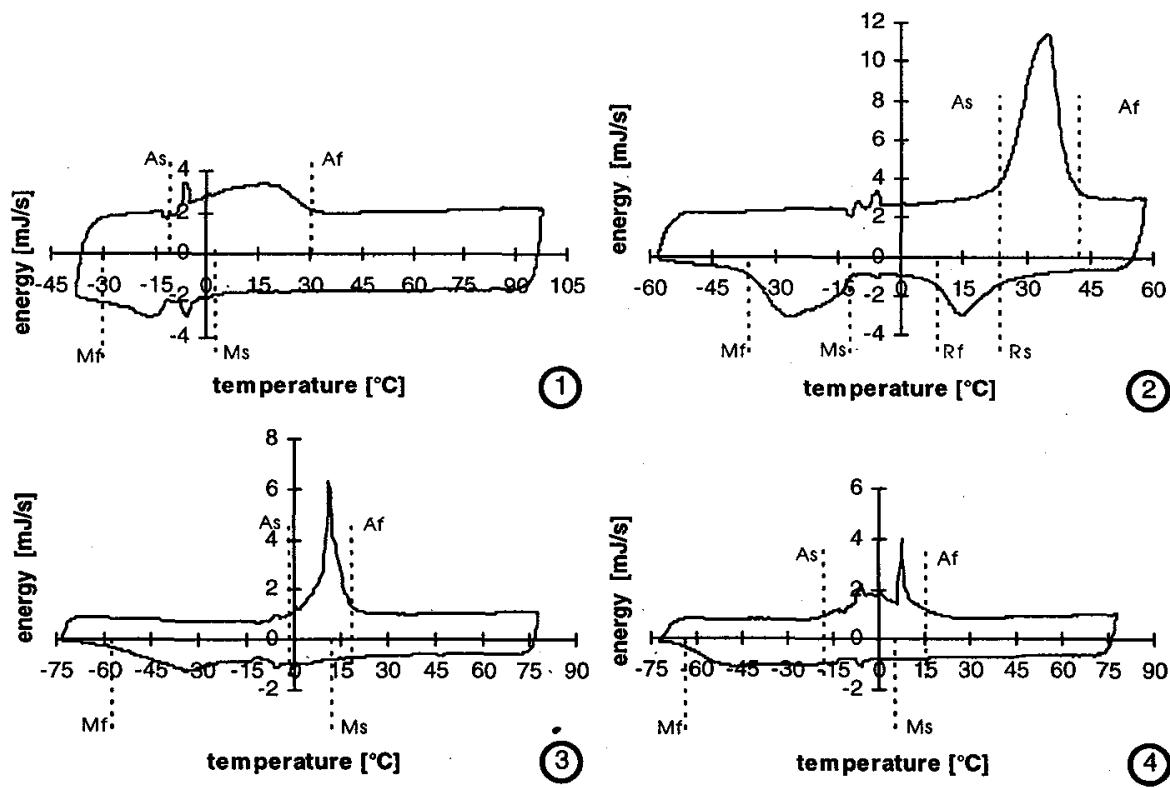

Figure 1: DSC scans of the NiTi alloy. 1: original cold deformed material. 2: after annealing at $500{ }^{\circ} \mathrm{C}$ for 30 minutes. 3: TWSME trained material, initial strain of $4.5 \% .4$ : TWSME trained material, initial strain of $6 \%$. 


\section{METHODS}

\subsection{Production of the NiTi Rings}

Twelve rings were made out of a NiTi alloy. The transformation temperatures were found by a Differential Scanning Calometry (DSC) measurement as shown in Fig. 1.1. This material was cold worked to a rod with a diameter of $8 \mathrm{~mm}$. The rod was machined to a diameter of $7 \mathrm{~mm}$ to remove the oxide layer. An initial center bore was made in a $30 \mathrm{~mm}$ section by spark discharge machining. Through that hole a wire was inserted for enlarging the inner diameter to $5 \mathrm{~mm}$ by wire spark discharge machining. By slicing 12 parts with an equal height of $2 \mathrm{~mm}$ off the tube the 12 rings were obtained. All rings had the same size with an overall accuracy of $0.05 \mathrm{~mm}$ : outer diameter of $7 \mathrm{~mm}$, inner diameter of $4.95 \mathrm{~mm}$ and a height of $2 \mathrm{~mm}$.

\subsection{Heat Treatment}

In order to "clear" the material from residual strains as a result of the cold deforming, the material had to be annealed at a certain temperature to allow recrystallisation and recovery of the internal strain. Strain recovery of the NiTi starts at $400{ }^{\circ} \mathrm{C}$, the higher the temperature becomes, the more homogeneous the resulting crystal structure will be, but above $700^{\circ} \mathrm{C}$ the mechanical properties like the plateau-stress will decrease rapidly [4].

Six rings were annealed at $500^{\circ} \mathrm{C}$ and six rings at $700^{\circ} \mathrm{C}$. Fig. 1.2 shows the DSC scan of the original material annealed at $500^{\circ} \mathrm{C}$. The start and finish temperatures become clearly distinguishable, austenite and martensite transformation trajectories become smaller, the $\mathrm{A}_{\mathrm{s}}$ temperature shifts to a higher temperature while the $\mathbf{M}_{\mathrm{s}}$ temperature shift to a lower temperature is much smaller. An important result is the appearance of a pre martensitic phase, the $\mathrm{R}$-phase $\left(\mathrm{R}_{\mathrm{s}} \sim 22^{\circ} \mathrm{C}\right)$. The results of annealing at $700^{\circ} \mathrm{C}$ are comparable except for the absence of the R-phase transition.

\subsection{Training Method}

We have chosen the following training method for the NiTi-rings to introduce the TWSME [5]:

Training by Constrained Temperature Cycling of deformed Martensite:

The component is first deformed in the martensitic phase (below $M_{f}$, strain up to the end of the martensitic plateau) to create a stress-biased martensitic microstructure. Next, the component is heated to $A_{f}$ while deformation is held and subsequently cooled again to below $M_{f}$. This temperature cycle is executed 50 times while the deformation is held.

Deformation of the rings is obtained by forcing them onto a conical pen. The forced change in diameter is not uniform over the height of the ring, but by choosing a proper conicity, the difference in diameter can be limited to less then $0.5 \%$, which is considered to be negligible. The end of the martensitic

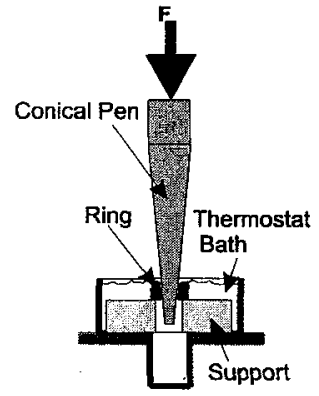

Figure 2: Deformation by forcing the conical pen through the ring plateau has been determined by forcing a number of rings on the conical pen while measuring the force and displacement. The end of the martensitic plateau was found at approximately $5 \%$ strain of the inner diameter. Heating and cooling found place in two separate baths: oil at $100^{\circ} \mathrm{C}$ and liquid nitrogen. The rings 50 times cycled through both baths while held deformed on the conical pen. A variation of this training method is initial deformation of the rings in the austenitic phase. 


\subsection{Determination of load-bearing capacity}

Two effects of the TWSME training on the rings are important in the design of the motor: the amount of shape change and the clamping force of the ring on the nail. In order to measure the TWSME on the change of the inner diameter and the maximal axial load-bearing the rings could withstand, a series of pens was made with a diameter ranging from $4.9 \mathrm{~mm}$ to $5.3 \mathrm{~mm}$ in random steps. The rings were cooled and mounted on the different pins and then heated to $25^{\circ} \mathrm{C}$ for transformation to the austenitic state and shape.

The rings were clamped on a cylindrical pen by sliding them on the pen in martensitic phase and subsequently heat them to the austenitic phase. The axial force was continuously increased, while the axial displacement of the ring over the pen was monitored. The maximum axial load-bearing capacity was reached at the moment the ring started to move over the pen.

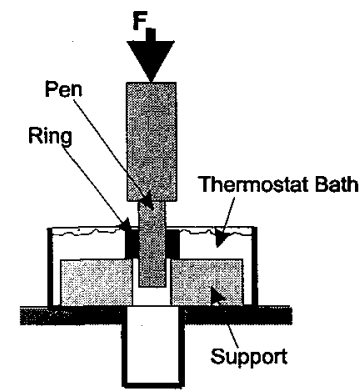

Figure 3: Setup for force/ displacement measurements

\section{RESULTS}

\subsection{Influence of the training in the NiTi rings}

Due to the internal stresses in the material caused by the TWSME-training the effect of the initial annealing diminishes and the transformation temperatures shift back to their original values. The decrease of the annealing effects is related to the amount of initial deformation (Fig. 1.3 and Fig. 1.4).

\subsection{TWSME displacement}

The resulting shape change or TWSME displacement was $\approx 1.5 \%$ of the original diameter. The difference of TWSME displacement of the inner ring diameter compared to $2 \%-3 \%$ in cases as mentioned in most literature (e.g. Stöckel et al [6]) are probably due to the bi-directional stresses in the ring. Most literature reflects on uni-directional stress cases.

\subsection{Force Generation}

The maximal axial load which the ring could withstand without moving depended on the difference in outer diameter of the pen and the inner diameter of the ring in the austenitic phase $(\Delta \mathrm{d})$. The larger $\Delta \mathrm{d}$ became the higher the axial load became. A $\Delta d=40 \mu \mathrm{m}$ resulted in a axial bearing load of $4100 \mathrm{~N}$. The maximum axial load in the tests was reached with a $\Delta \mathrm{d}=60 \mu \mathrm{m}$ ( $>6000 \mathrm{~N}$, the ring did not move). With this $\Delta$ d it became difficult to mount the ring in martensitic state on the pen without force, which implied that this $\Delta d$ was so large that the total TWSME of the shape change was insufficient for practical application.

Table 1: Test results of TWSME training on NiTi-rings $\left(T=25^{\circ} \mathrm{C}\right)$

\begin{tabular}{|c|c|c|c|c|c|}
\hline Ring & Heat treatment & $\begin{array}{c}\text { Initial Deformation } \\
\text { Phase }\end{array}$ & $\begin{array}{c}\text { Initial } \\
\text { Strain }\end{array}$ & $\Delta \mathrm{d}$ & $\begin{array}{c}\text { Maximum } \\
\text { Axial Force }\end{array}$ \\
\hline 6 & $500^{\circ} \mathrm{C} / 30 \mathrm{~min} . /$ Argon & Martensite & $4.5 \%$ & $\approx 40 \mu \mathrm{m}$ & $4100 \mathrm{~N}$ \\
\hline 7 & $500^{\circ} \mathrm{C} / 30 \mathrm{~min}$. / Argon & Martensite & $5.5 \%$ & $\approx 36 \mu \mathrm{m}$ & $3500 \mathrm{~N}$ \\
\hline 9 & $700^{\circ} \mathrm{C} / 60 \mathrm{~min} . /$ Argon & Austenite & $6.0 \%$ & $\approx 60 \mu \mathrm{m}$ & $>6000 \mathrm{~N}$ \\
\hline 10 & $700^{\circ} \mathrm{C} / 60 \mathrm{~min} . /$ Argon & Martensite & $6.0 \%$ & $\approx 43 \mu \mathrm{m}$ & $5200 \mathrm{~N}$ \\
\hline
\end{tabular}


The tests showed no difference in force generation between rings which were initially deformed in the austenite or martensite phase. The resulting clamping forces are slightly higher when the initial deformation exceeds the limits of the martensitic plateau [table 1].

\section{DISCUSSION}

This study shows that it is possible to train the TWSME into a ring shaped element. The results showed that the rings are useful in the proposed design for an intramedullairy leg lengthening device. The clamping force generated by the TWSME is high enough to bear the weight of a patient and dynamic forces during (careful) walking and the generated TWSME displacement is large enough to loosen the rings in the martensitic phase for free movement over a central pen. The force measured in this study is the axial force on the pen through the ring. There were two reasons to take this force as the reference: this force represents the actual workload in leg elongations and furthermore it is very difficult to make an accurate measurement of the radial clamping force of a ring with a $5 \mathrm{~mm}$ bore. Furthermore the axial bearing load exceeds the calculations based on a friction-based mounting of the ring on the pen. The ring deformed the pen in such a way that a combination of shape-closed and friction-based mounting was created which could withstand the high axial loads.

While annealing at a lower temperature results in comparable mechanical results and equally well defined start and finish temperatures, earlier studies found that the appearance of a R-phase theoretically would obstruct the TWSME [7]. This is in contradiction with the results in this study. Apparently the influence of the R-phase on the TWSME is negligible in practical use.

As shown in the tests the $\Delta \mathrm{d}$ between the ring and the pen is the most critical factor concerning maximal axial load bearing. The initial amount of deformation is of less influence, but tests showed that initial deformation to just above the end of the martensitic plateau results in slightly higher axial loadbearing capacity. The disadvantage of high initial strains are the diminishing effects of prior annealing.

One of the problems in the proposed practical usage is the shifting of the transformation temperatures after training. It would be useful to fully investigate the relation between temperature shift and training procedure to be able to make an accurate prediction of the final transformation temperatures. In the case of medical usage these are especially important as a result of a limited temperature range for implants in the human body.

\section{References}

[1] Ilizarov G.A., Clin. Orthop. 250 (1990) 8.

[2] Raschke M.J., Mann J.W., Oedekoven G. and Claudi B.F., Clin. Orthop. 282 (1992) 233.

[3] Aalsma A.M.M., Hekman E.E.G., Stapert J.W.J.L., Grootenboer H.J., Inrichting voor het onderling verplaatsen van twee objecten, Ned Octrooi, No. 1004873, (Bureau voor Ind. Eigendom, Rijswijk, 1996).

[4] Jackson C.M., Wagner H.J. and Wasilewski R.J., 55-Nitinol-The alloy with a memory: its physical metallurgy, properties and application (NASA, Washington D.C., 1972) pp. 63-65.

[5] Duerig T.W., Melton K.N., Stöckel D. and Wayman C.M., Engineering aspects of Shape Memory Alloys (Butterworth-Heinemann, London, 1990) pp. 200-206.

[6] Stöckel D., Hornbogen E., Ritter F. and Tautzenberger P., Legierungen mit Formgedächtnis (Expert Verlag, Ehningen bei Böblingen, 1988) pp. 42-46.

[7] Yinong Lui and McCormick P.G., Acta Metallurgica 38 (1990) 1321. 